УДК 581.14:535.212;581.19

\title{
ПОЛУЧЕНИЕ ЛЕКАРСТВЕННОГО РАСТИТЕЛЬНОГО СЫРЬЯ КАТАРАНТУСА РОЗОВОГО С ИСПОЛЬЗОВАНИЕМ СВЕТОДИОДНОГО ОСВЕЩЕНИЯ В УСЛОВИЯХ ЗАКРЫТОГО ГРУНТА
}

\author{
(C) О.В. Молчан ${ }^{1 *}$, В.И. Привалов ${ }^{2}$ В.О. Петринчик ${ }^{1}$ Н.И. Астасенко ${ }^{1}$ \\ ${ }^{1}$ Институт экспериментальной ботаники им. В.Ф. Купревича НАН Беларуси, \\ ул. Академическая, 27, Минск, 200072 (Республика Беларусь), \\ e-mail: olga_molchan@mail.ru \\ ${ }^{2}$ Центр светодиодных и оптоэлектронных технологий НАН Беларуси, \\ Логойский тракт,22, Минск, 220012 (Республика Беларусь)
}

Установлены режимы светодиодного освещения, эффективные для получения сырья растений катарантуса розового (лат. Catharanthus roseus (L.) G. Don, сем. Аросуnaceae) в условиях закрытого грунта. Показано, что максимальное накопление сухой массы всех органов растения обеспечивается светодиодным освещением с соотношением синего и красного света $(\mathrm{C}: \mathrm{K})$, равным $1: 4$, и плотностью потока фотонов (ППФ) 500 мкмоль $\mathrm{m}^{-2} \cdot \mathrm{c}^{-1}$. При освещении с соотношением $\mathrm{C}: \mathrm{K}$, равным $1: 1,3$ и ППФ 200 мкмоль $\mathrm{m}^{-2} \cdot \mathrm{c}^{-1}$, наблюдалось замедление ростовых процессов, снижение интенсивности цветения и накопления сухой массы C. roseus. Однако данный режим оказался эффективным для стимуляции процессов биосинтеза и накопления терпеновых индольных алкалоидов в листьях и корнях, а также фенольных соединений в надземной части растений. Для образования корневой системы C. roseus и накопления в ней фенольных соединений оптимальными были варианты освещения с самым высоким из протестированных уровнем ППФ - 500 мкмоль $\cdot \mathrm{M}^{-2} \cdot \mathrm{c}^{-1}$.

Таким образом, наибольший выход фармакологически ценных терпеновых индольных алкалоидов листьев C. roseus

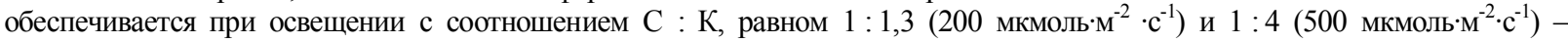
$123,54 \pm 1,42$ и $127,21 \pm 2,54$ мг/растение, соответственно. Максимальный выход алкалоидов, накапливающихся в корневой системе, отмечен при освещении с ППФ 500 мкмоль $\mathrm{M}^{-2} \cdot \mathrm{c}^{-1} \mathrm{c}$ и соотношением $\mathrm{C}: \mathrm{K}$, равным $1: 2,5$ и $1: 4-$ $99,14 \pm 5,93$ и 89,29 $\pm 7,13$ мг/растение, соответственно.

Ключевые слова: Catharanthus roseus G. Don, терпеновые индольные алкалоиды (ТИА), сухая масса, светодиодное (LED) освещение, фенольные соединения.

Работа выполнена при поддержке Белорусского фонда фундаментальных исследований (грант №516K-050).

\section{Введение}

Многие фармакологически ценные вторичные метаболиты лекарственных растений до сих пор не удается получить с помощью химического синтеза и их выделяют только из растительного сырья [1, 2].

Молчан Ольга Викторовна - заведующая лабораторией водного обмена и фотосинтеза, доцент, кандидат биологических наук, тел. +375-17-284-20-12, e-mail: olga_molchan@mail.ru

Привалов Виктор Иванович - тел. +375-17-281-13-62, e-mail: olga_molchan@mail.ru

Петринчик Виктория Олеговна - младший научный сотрудник, тел. +375-17-284-20-12,

e-mail:olga_molchan@mail.ru

Астасенко Николай Игнатьевич - научный сотрудник, тел. +375-17-284-20-12, e-mail: olga_molchan@mail.ru
К таким растениям относится и катарантус розовый, Catharanthus roseus (L.) G. Don, семейства Apocynaceae, содержащий терпеновые индольные алкалоиды (ТИА) [3, 4]. ТИА C. roseus характеризуются широким спектром биологической активности и представляют большой интерес для фармацевтической промышленности [3]. В настоящее время из различных органов этого растения выделяют около 150 индольных алкалоидов мономерной и димерной природы. Среди мономерных - ката-

\footnotetext{
* Автор, с которым следует вести переписку.
} 
рантин, леурозин, иохимбин, ибогаин, аймалицин, лохнерин, тетрагидроальстонин, виндолин, резерпин, серпентин и другие $[4,5]$. Фармакологические препараты, содержащие мономерные алкалоиды C. roseus, обладают гипотензивным, сосудорасширяющим и диуретическим свойствами, что позволяет использовать их при лечении сердечно-сосудистых заболеваний, протекающих с высоким артериальным давлением [2]. Кроме того, данные алкалоиды применяют при лечении стоматита, диабета, простудных и других заболеваний как противовирусные и противовоспалительные, а также используют как противомалярийные и снижающие уровень холестерина в крови препараты [3]. Кроме мономерных, в катарантусе розовом обнаружено около 25 алкалоидов димерной природы. Повышенное внимание исследователей и фармацевтов к C. roseus обусловлено синтезом в растении коммерчески ценных ТИА бис-индольной природы, винбластина (1 млн \$/кг), используемого для комплексной терапии лимфогранулематоза, и винкристина (3,5 млн \$/кг), применяемого при лечении различных видов лейкемии, гематосаркомы, карциномы, меланомы, лейкоза и др., а также мономерного алкалоида аймалицина (2000 \$/кг) гипотонического и антиаритмического действия [6]. Димерные алкалоиды C. roseus накапливаются в основном в листьях, а аймалицин - преимущественно в корнях растений [7]. Основными алкалоидами надземной части растения являются катарантин и виндолин - мономерные предшественники винбластина и винкристина $[7,8]$. В корневой системе преобладают аймалицин и серпентин. Исследования последних лет показали также возможность применения серпентина при лечении болезни Альцгеймера [9].

Кроме алкалоидов в сырье растений $C$. roseus обнаруживается широкий спектр фенольных соединений, включающий фенольные кислоты, простые фенилпропаноиды, флавоноиды, в том числе антоцианы, проявляющие антиоксидантную, противовоспалительную и иммуномодулирующую активность [10].

Однако нужно отметить, что высокоценные вторичные метаболиты синтезируются в C. roseus в незначительном количестве, при этом их содержание зависит от условий культивирования [11]. Еще одной группой факторов, затрудняющих использование сырья C. roseus, являются экологические. Так, C. roseus тропическое растение, и в условиях восточно-европейского климата может произрастать только в оранжерейной культуре. Поэтому при необходимости постоянно увеличивать долю фармацевтических субстанций отечественного производства представляется важным развивать технологии, создающие альтернативную сырьевую базу лекарственных растений [12]. В этом случае особое значение приобретает разработка и внедрение современных инновационных технологий, позволяющих получать на основе биомассы культивируемых растений экологически чистые препараты, содержащие необходимые фармакологически активные вещества в достаточном количестве независимо от климатических условий. Одной из таких технологий является культивирование растений с использованием светодиодного (Light Emission Diodes (LED) излучения $[13,14]$. Разработка и внедрение энергосберегающих технологий в различные области человеческой деятельности является актуальной задачей на современном этапе развития экономик практически всех стран мира. Наиболее энергоэффективные источники для культивирования растений в настоящее время могут быть реализованы на основе светодиодов. Кроме того, малая ширина спектра излучения светодиодов является фактором, позволяющим создавать облучатели с оптимальным для каждого вида растений спектральным распределением, а также независимо регулировать плотность потока фотонов и продолжительность излучения в пределах каждой спектральной составляющей $[15,16]$.

Важно отметить, что изучение регуляции биосинтеза фармакологически ценных вторичных метаболитов, а также роста и развития лекарственных растений с помощью различных режимов светодиодного излучения является сегодня одним из перспективных направлений фундаментальных исследований [12, 15]. При этом к настоящему времени в литературе очень мало данных о влиянии LED-излучения на физиолого-биохимические параметры лекарственных растений, в том числе C. roseus, при их длительном культивировании $[12,15]$. А уже опубликованные работы посвящены в основном эффектам монохроматического освещения в красной или синей области спектра на рост растений и содержание некоторых алкалоидов [12], в то время как для роста и развития растений критически важными являются все части спектра фотосинтетически активной радиации. Следует также отметить, что исследований влияния LED-освещения на накопление фенольных соединений $C$. roseus вообще не проводилось.

В связи с вышесказанным чрезвычайно важными и актуальными являются разработка эффективных режимов LED-освещения при культивировании растений C. roseus для получения фармакологически ценного сырья. Целью данной работы было исследование влияния различных режимов светодиодного освещения на ростовые процессы, физиолого-биохимические параметры, а также накопление биомассы и фармакологически ценных вторичных метаболитов - алкалоидов и фенольных соединений - различными органами растений $C$. roseus. 


\section{Экспериментальная часть}

Данное исследование было проведено в 2015-2016 гг. Материалом исследования служили растения C. roseus, собранные в фазе цветения на 124-е сутки культивирования.

C. roseus - вечнозеленый многолетний полукустарник или травянистое прямостоячее восходящее растение до 1 м высотой [4]. Листья накрест супротивные, простые, цельные, ярко-зеленые, черешчатые, овальные или продолговатые. Листовая пластинка с 7-11 парами боковых жилок, голая или рассеянно опушенная с нижней стороны (особенно по жилкам и краю листовой пластинки). Цветки одиночные, расположены в пазухах листьев или собраны в малоцветковое соцветие. Цветоножки голые, короткие, во много раз короче листьев. Околоцветник двойной. Чашечка пятичленная, сростная у основания, голая или слабоопушенная. Чашелистики линейно-ланцетные, острые. Венчик пятичленный, сростнолепестный, колесовидный, с длинной цилиндрической трубкой и с плоским отгибом. Окраска отгиба венчика обычно розовая с красным зевом. Встречаются сорта с белыми или пурпурными венчиками и более темным или светлым красноватым, беловатым или желтым опушенным зевом. Андроцей пятичленный. Пыльники свободные, продолговатые, прилегают к широкому рыльцу. Тычиночные нити короткие, прикреплены к верхней расширенной части трубки венчика и чередуются с лопастями отгиба. Гинецей апокарпный, из двух слабоопушенных или голых плодолистиков. Завязь с многочисленными семяпочками. Плоды - серповидно-изогнутые зеленые парные листовки, длиной до 3,5 см и толщиной 3 мм с очень короткой плодоножкой. В каждой листовке содержится до 20 25 семян. Семена темно-коричневые, продолговатые, цилиндрические, бугорчатые [4].

Семена C. roseus стерилизовали в течение 30 с в растворе $70 \%$ этанола, промывали стерильной дистиллированной водой и оставляли набухать в течение 12 ч. Семена проращивали в стерильных чашках Петри диаметром $10 \mathrm{~cm}$ на влажной фильтровальной бумаге при $25^{\circ} \mathrm{C}$. 10-дневные проростки переносили в субстрат и далее культивировали при $25^{\circ} \mathrm{C}$. В качестве субстрата использовали коммерческий грунт «Теrra vita» (Санкт-Петербург) на основе смеси верховых торфов с добавлением природных структурирующих компонентов, микро- и макроэлементов, согласно информации производителя. Полив растений проводили при уменьшении веса субстрата на 25-30\% от полной влагоемкости с дренированием. Используемый для полива раствор содержал 300 мг/л $\mathrm{KNO}_{3}, 700$ мг/л $\mathrm{Ca}\left(\mathrm{NO}_{3}\right)_{2}, 220$ мг/л $\mathrm{NH}_{4} \mathrm{NO}_{3}, 420$ мг/л $\mathrm{KH}_{2} \mathrm{PO}_{4}, 280$ мг/л $\mathrm{MgSO}_{4}, 16$ мг/л $\mathrm{FeSO}_{4}, 2$ мг/л $\mathrm{H}_{3} \mathrm{BO}_{3}, 3$ мг/л $\mathrm{MnSO}_{4}, 1,5$ мг/л $\mathrm{ZnSO}_{4}, 2$ мг/л $\mathrm{CuSO}_{4}, 0,15$ мг/л $\left(\mathrm{NH}_{4}\right)_{2} \mathrm{MoO}_{4}$, $\mathrm{pH}$ 5,5 [11]. Растения C. roseus культивировали при люминесцентном (контроль) и светодиодном освещении различного спектрального состава и интенсивности, с фотопериодом 16/8 часов (свет/темнота). Были использованы три специализированные системы светодиодного освещения, изготовленные в Центре светодиодных и оптоэлектронных технологий НАH Беларуси. Спектральные характеристики систем LED-освещения приведены в таблице 1. Для организации освещения использовали излучение всех длин волн видимого света с варьируемым соотношением квантов синего (450-510 нм) и красного (630-700 нм) спектральных диапазонов (С : К) и плотностью потока фотонов (ППФ) (табл. 1). Спектр излучения и ППФ каждого из вариантов LEDосвещения были одинаковы на протяжении всего времени выращивания растений. Контроль параметров проводили с помощью спектрорадиометра CAS140CT (Германия).

Конструкция установки позволяла обеспечить освещение с соотношением $\mathrm{C}:$ К, равным $1: 1,3$; $1: 2,5$ или $1: 4$ и ППФ, равным 200 либо 500 мкмоль квантов $\cdot \mathrm{M}^{-2} \cdot \mathrm{c}^{-1}$ на уровне верхушки культивируемых растений. Таким образом, было организовано 5 вариантов светодиодного освещения растений (СД 1-5), характеризующихся различной интенсивностью (ППФ) и соотношением синего и красного света (С : К) в спектре (табл. 1). В качестве контрольного было использовано люминесцентное освещение. Соотношение $\mathrm{C}:$ К при люминесцентном освещении составляло $1: 2,5$, интенсивность излучения -200 мкмоль $\cdot \mathrm{M}^{-2} \cdot \mathrm{c}^{-1}$.

Для получения сухого сырья листья, стебли и корни сушили раздельно при $30-35{ }^{\circ} \mathrm{C}$. Высушенную до абсолютно сухой массы растительную ткань измельчали до состояния пудры и использовали для экстракции вторичных метаболитов. Влажность сырья в процессе хранения не превышала 9,0\%. Выделение алкалоидов индольного ряда из различных органов C. roseus проводили согласно методу, описанному в работе [17]. Содержание суммы фенольных соединений определяли по стандартной методике с реактивом Фолина-Чокальтеу [18]. Содержание хлорофилла в течение всего периода культивирования растений оценивали в полностью развитых листьях с помощью недеструктивного оптического сенсора Dualex (FORCE-A, Orsay, France) [19]. Исследования проводили в 5 биологических повторностях, используя не менее 10 растений для каждого варианта освещения. Для обработки полученных результатов применяли стандартные методы вариационной статистики. Данные приведены как среднее арифметическое (x) \pm ошибка средней величины $\left(\mathrm{S}_{\mathrm{x}}\right)[20]$. 
Таблица 1. Спектральные характеристики специализированных систем светодиодного освещения для культивирования растений C. roseus

\begin{tabular}{|c|c|c|c|c|c|c|}
\hline \multirow[t]{2}{*}{$\begin{array}{c}\text { Диапазон длин } \\
\text { волн, нм }\end{array}$} & \multicolumn{2}{|c|}{$\begin{array}{c}\text { СД } 1 \\
\left(\text { ППФ } 200 \text { мкмоль } \cdot \mathrm{M}^{-2} \cdot \mathrm{c}^{-1}\right)\end{array}$} & \multicolumn{2}{|c|}{$\begin{array}{c}\text { СД } 2 \\
\left(\text { ППФ } 200 \text { мкмоль } \cdot \mathrm{m}^{-2} \cdot \mathrm{c}^{-1}\right) \\
\text { СД } 3 \\
\left(\text { ППФ } 500 \text { мкмоль } \cdot \mathrm{m}^{-2} \cdot \mathrm{c}^{-1}\right)\end{array}$} & \multicolumn{2}{|c|}{$\begin{array}{c}\text { СД 4 } \\
\left(\text { ППФ } 200 \text { мкмоль } \cdot \mathrm{M}^{-2} \cdot \mathrm{c}^{-1}\right) \\
\text { СД } 5 \\
\left(\text { ППФ } 500 \text { мкмоль } \cdot \mathrm{M}^{-2} \cdot \mathrm{c}^{-1}\right)\end{array}$} \\
\hline & ППФ", \% & $C: K^{* * *}$ & ППФ, \% & $\mathrm{C}: \mathrm{K}$ & ППФ, \% & $\mathrm{C}: \mathrm{K}$ \\
\hline $400-500$ & $20-25$ & \multirow{4}{*}{$1: 1,3$} & $15-20$ & \multirow{4}{*}{$1: 2,5$} & $10-15$ & \multirow{4}{*}{$1: 4$} \\
\hline $500-600$ & $40-45$ & & $30-35$ & & $25-30$ & \\
\hline $600-700$ & $25-30$ & & $40-45$ & & $45-50$ & \\
\hline $700-800$ & менее10 & & менее 10 & & менее 10 & \\
\hline
\end{tabular}

Примечание. * плотность потока фотонов; **соотношение синего и красного света в спектре излучения.

\section{Обсуждение результатов}

Физиолого-биохимические параметры растений. При культивировании C. roseus в условиях закрытого грунта основные параметры микроклимата можно регулировать для обеспечения оптимального роста и развития растений $[8,12,21]$. При этом на первом плане - проблемы освещения, которое при минимальных затратах должно отвечать требованиям растений, обеспечивать и позволять регулировать их рост и накопление вторичных метаболитов в течение достаточно длительного периода вегетации для получения фармакологически ценного растительного сырья. В связи с этим было изучено влияние различных режимов светодиодного освещения на морфометрические и биохимические параметры растений C. roseus. Для оценки физиологического состояния культивируемых растений проводили анализ динамики изменений высоты растений (интенсивность роста), количества образовавшихся цветков (интенсивности цветения) и содержания хлорофилла в листьях (активности фотосинтетического аппарата) в течение 124 сут культивирования. Результаты представлены на рисунке.

Уже в течение первых 98 сут культивирования была установлена достоверная стимуляция скорости ростовых процессов $C$. roseus при их освещении светом с соотношением $\mathrm{C}: \mathrm{K}$, равном $1: 4$, вне зависимости от интенсивности освещения (варианты СД 4 и СД 5, рис. А). К 105-м суткам культивирования обнаруживается также значительное замедление ростовых процессов у растений варианта СД 1, освещаемых светом, спектральный состав которого наиболее приближен к естественному (с соотношением С : К, равным $1: 1,3$ ). При дальнейшем культивировании отличия высоты растений C. roseus данных вариантов от контрольных становились более выраженным. Вместе с тем, только к 112 суткам культивирования отмечается достоверная по сравнению с контрольным ЛЛ вариантом стимуляция роста растений, культивируемых при соотношении $\mathrm{C}:$ К, равном $1: 2,5$ и уровне ППФ 200 мкмоль $\mathrm{M}^{-2} \cdot \mathrm{c}^{-1}$ (вариант СД 2). При этом нужно отметить, что высота растений, освещаемых светом с такими же спектральными характеристиками, но более высоким уровнем ППФ (вариант СД 3) от контрольного не отличалась в течение всего времени культивирования.

Важно было оценить также влияние различных режимов освещения на образование генеративных органов C. roseus, поскольку сбор сырья осуществляют в период цветения. Так, уже в первые 98 сут культивирования стимуляция цветения наблюдается у растений при LED-освещении с соотношением C : К, равном $1: 4$ и ППФ 200 и 500 мкмоль $\cdot \mathrm{m}^{-2} \cdot \mathrm{c}^{-1}$ (рис. Б). При дальнейшем культивировании стало очевидным, что большее по сравнению с контрольным вариантом количество цветков отмечается при увеличении доли красного света (600-700 нм) в спектре. Наименее эффективным для образования генеративных органов C. roseus оказался вариант освещения СД 1, спектральный состав которого характеризовался соотношением С : К, равным $1: 1,3$ и уровнем ППФ 200 мкмоль $\cdot \mathrm{M}^{-2} \cdot \mathrm{c}^{-1}$ (рис. Б).

Поскольку подбор оптимального спектра для культивирования растений касается варьирования уровня фотосинтетически активной радиации (ФАР), важным физиологическим параметром является содержание фотосинтетических пигментов листа, непосредственно отражающее состояние фотосинтетического аппарата. Освещение - основной фактор, регулирующий содержание фотосинтетических пигментов в листьях, и таким образом их фотосинтетическую и биосинтетическую активности. Как видно на рисунке (рис. В), значительных отличий в содержании хлорофилла в листовом аппарате растений разных вариантов обнаружено не было. Несколько большим по сравнению с контрольным был уровень фотосинтетических пигментов в листьях растений вариантов СД 3 и СД 5 с максимальной интенсивностью освещения 500 мкмоль $\cdot \mathrm{M}^{-2} \cdot \mathrm{c}^{-1}$ (рис. 1В). При этом содержание хлорофилла в листьях растений всех вариантов варьировало в диапазоне 38-47 мг/см², что свидетельствует об удовлетворительном состоянии фотосинтетического аппарата в течение всего периода культивирования (рис. В). 

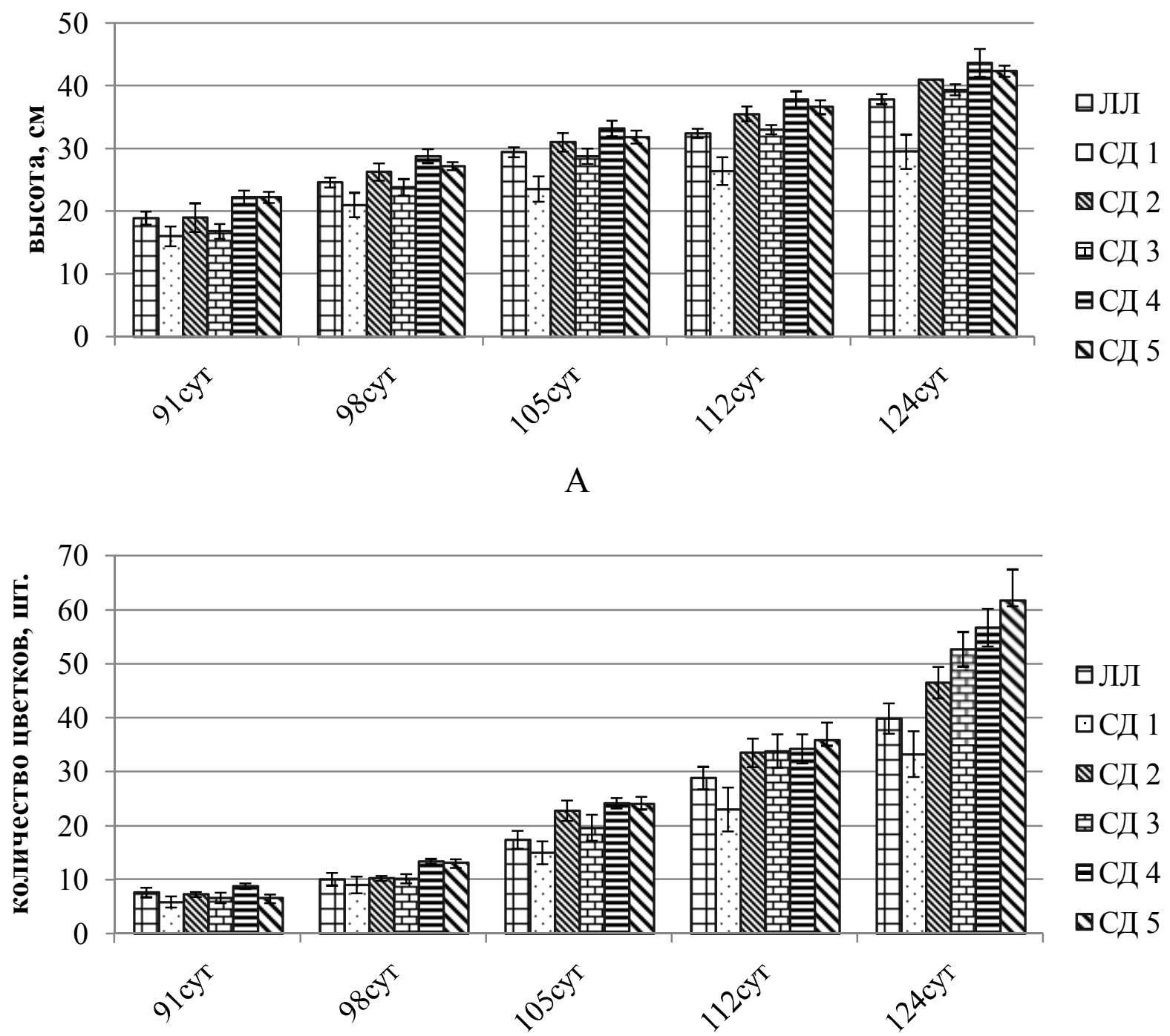

Б

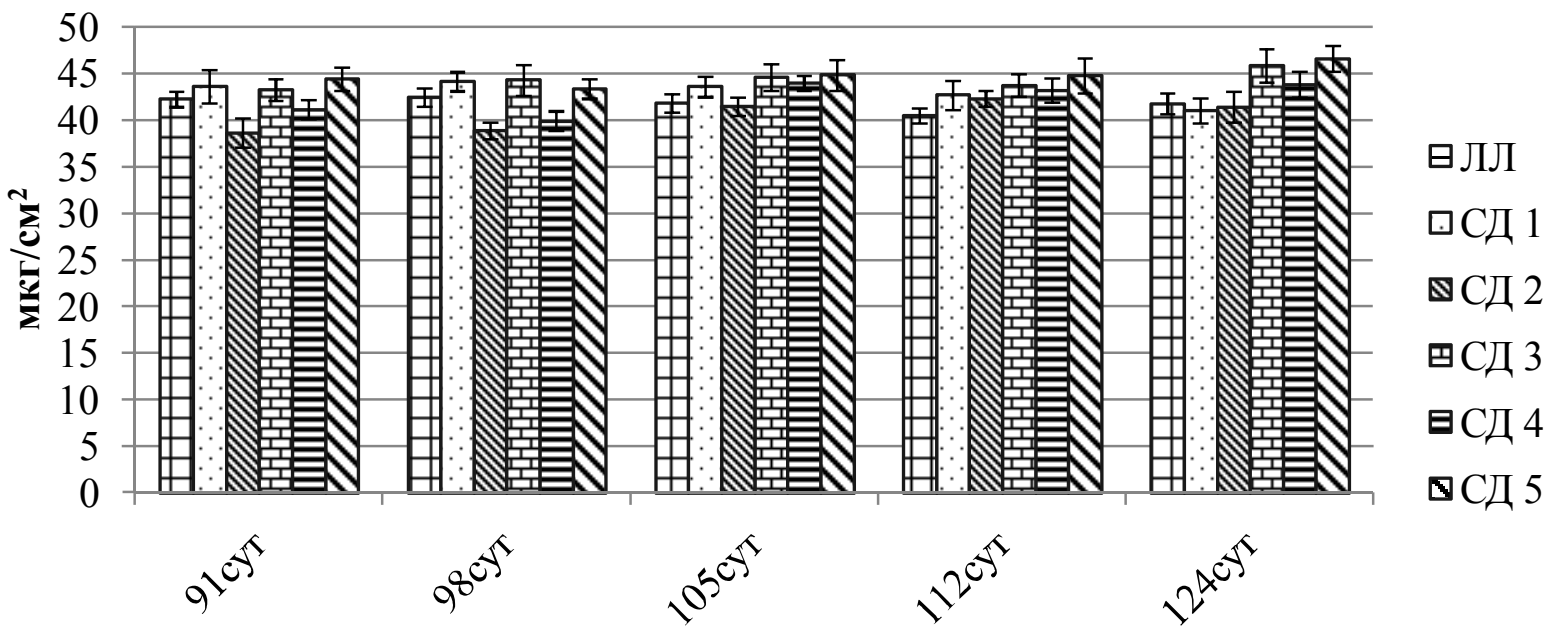

B

Влияние различных режимов освещения на высоту (А), количество цветков (Б) и содержание хлорофилла в листьях (В) растений Catharanthus roseus 
Продуктивность (накопление сухой массы), содержание фенольных соединений и алкалоидов в различных органах растений. Далее была проведена оценка влияния различных типов освещения на продуктивность (накопление сухой массы) растений C. roseus. Определяли сухую массу листьев, стеблей и корневой системы. В результате установлено, что при всех вариантах LED-освещения, кроме СД 1, продуктивность растений была выше контрольного ЛЛ варианта (табл. 2). В Реестре лекарственных средств РФ в качестве растительного сырья значатся листья катарантуса розового (Folia Catharanthi), накапливающие димерные алкалоиды [22]. Качество сырья регламентируется согласно ВФС 42-1106-81 [23]. В данной работе образование листового аппарата достаточно эффективно стимулировалось практически всеми вариантами LED-освещения с повышенным содержанием красного света в спектре излучения (СД 2 - СД 5). Максимальной сухой массой листьев и стеблей характеризовались растения варианта СД 5, культивируемые при соотношении $\mathrm{C}: \mathrm{K}$, равном $1: 4$ и ППФ 500 мкмоль $\mathrm{M}^{-2} \cdot \mathrm{c}^{-1}$.

Источником фармакологически ценных ТИА может являться и корневая система C. roseus, накапливающая аймалицин, алкалоид гипотонического действия. Для образования корневой системы наиболее эффективными были оба варианта LED-освещения с высоким уровнем ППФ - 500 мкмоль м $^{-2} \cdot \mathrm{c}^{-1}(\mathrm{CД} 3$ и СД 5), независимо от спектра излучения. Важно также отметить, что при освещении с соотношением С : К, равным $1: 1,3$, наблюдалось снижение продуктивности растений по сравнению с контролем (ЛЛ). Максимальная стимуляция накопления сухой массы всех органов растений была отмечена при светодиодном освещении с соотношением $\mathrm{C}: \mathrm{K}$, равным $1: 4$ и высоким уровнем ППФ (500 мкмоль $\left.\mathrm{M}^{-2} \cdot \mathrm{c}^{-1}\right)$.

Также оценивали содержание суммы фенольных соединений в исследуемых растениях. Максимальный уровень накопления соединений фенольной природы был характерен для листьев (4-5 мг/г сухой массы), минимальный - для стеблей (1,7-2,3 мг/г сухой массы) C. roseus (табл. 2). При этом под светодиодным освещением листья растений накапливали больше фенольных соединений, чем под люминесцентным. В то же время существенных отличий в содержании фенольных соединений в листьях растений, культивируемых при различных режимах светодиодного освещения, не обнаружено. Несколько более высоким $(5,33 \pm 0,04$ мг/Г сухой массы) по сравнению с контрольным вариантом $(4,04 \pm 0,09$ мг/г сухой массы) был уровень фенольных соединений в листьях растений, культивируемых при соотношении С : К, равном

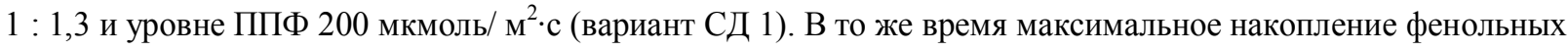
соединений в стеблях $C$. roseus обнаружено при вариантах освещения СД 1, СД 4 и СД 5. Также можно отметить, что увеличение количества красного света в спектре излучения (варианты СД 3, СД 4 и СД 5) приводило к стимуляции накопления фенольных соединений в корнях до $3,11 \pm 0,12,2,84 \pm 0,04$, $3,15 \pm 0,10$ мг/г сухой массы, соответственно.

С точки зрения практического использования сырья C. roseus важным является определение условий культивирования растений, обеспечивающих оптимальное соотношение между накоплением фитомассы и биосинтезом фармакологически ценных БАВ. В результате анализа общего содержания суммы фенольных соединений в одном растении (мг/растение) было установлено, что максимальное накопление веществ фенольной природы происходит при светодиодном освещении с повышенным содержанием красного света в спектре (варианты СД 3, СД 4 и СД 5). При этом, чем больше интенсивность света (варианты СД 3 и СД 5), тем больше фенольных соединений накапливается в листьях (27-33 мг) и в корнях (7-8 мг) растения (табл. 2).

Особая коммерческая ценность сырья растений $C$. roseus определяется накоплением в его надземной части и корневой системе индольных алкалоидов. Важно отметить, что их состав и содержание существенно варьируют в различных органах растения и зависят от генотипа и условий культивирования. Согласно литературным данным, максимальное количество суммы алкалоидов в данном растении обнаружено в корне и, в основном, колеблется в пределах от 2 до 3\%, достигая в ряде работ 9\% при культивировании в закрытом грунте $[11,17]$. Содержание же суммы алкалоидов в листьях составляет в среднем около 1,5-2,5\%, достигая $5,6 \%$ по данным некоторых исследователей $[11,17]$. Поэтому в данной работе особенно важным представлялось оценить влияние LED-освещения на содержание алкадоидов в различных органах C. roseus. 
Таблица 2 - Влияние различных типов освещения на накопление сухой массы, фенольных соединений и алкалоидов растениями C. roseus

\begin{tabular}{|c|c|c|c|c|c|c|}
\hline Органы & ЛЛ & СД 1 & СД 2 & СД 3 & СД 4 & СД 5 \\
\hline \multicolumn{7}{|c|}{ Продуктивность (г сухой массы/растение) } \\
\hline Листья & $4,61 \pm 0,08$ & $4,26 \pm 0,44$ & $5,87 \pm 0,17$ & $5,82 \pm 0,13$ & $5,60 \pm 0,18$ & $6,86 \pm 0,15$ \\
\hline Стебли & $2,68 \pm 0,18$ & $2,58 \pm 0,28$ & $3,42 \pm 0,42$ & $3,75 \pm 0,11$ & $3,79 \pm 0,41$ & $4,71 \pm 0,40$ \\
\hline Корни & $1,41 \pm 0,06$ & $1,23 \pm 0,11$ & $1,55 \pm 0,18$ & $2,51 \pm 0,18$ & $1,88 \pm 0,21$ & $2,50 \pm 0,08$ \\
\hline \multicolumn{7}{|c|}{ Содержание фенольных соединений (мг/г сухой массы) } \\
\hline Листья & $4,04 \pm 0,09$ & $5,33 \pm 0,04$ & $4,60 \pm 0,27$ & $4,76 \pm 0,03$ & $4,61 \pm 0,07$ & $4,89 \pm 0,08$ \\
\hline Стебли & $2,02 \pm 0,04$ & $2,25 \pm 0,08$ & $1,76 \pm 0,03$ & $1,90 \pm 0,04$ & $2,20 \pm 0,04$ & $2,27 \pm 0,07$ \\
\hline Корни & $2,53 \pm 0,09$ & $2,42 \pm 0,19$ & $1,50 \pm 0,03$ & $3,11 \pm 0,12$ & $2,84 \pm 0,04$ & $3,15 \pm 0,10$ \\
\hline \multicolumn{7}{|c|}{ Выход фенольных соединений (мг/растение) } \\
\hline Листья & $18,62 \pm 0,93$ & $22,71 \pm 0,47$ & $27,05 \pm 0,34$ & $27,70 \pm 0,38$ & $25,82 \pm 0,9$ & $33,54 \pm 1,17$ \\
\hline Стебли & $5,42 \pm 0,21$ & $2,76 \pm 0,25$ & $6,04 \pm 0,38$ & $7,12 \pm 0,14$ & $8,31 \pm 0,37$ & $10,76 \pm 0,64$ \\
\hline Корни & $3,58 \pm 0,17$ & $3,02 \pm 0,34$ & $2,34 \pm 0,29$ & $7,85 \pm 0,50$ & $5,33 \pm 0,27$ & $7,86 \pm 0,16$ \\
\hline \multicolumn{7}{|c|}{ Содержание алкалоидов (\%) } \\
\hline Листья & $2,01 \pm 0,18$ & $2,90 \pm 0,06$ & $2,0 \pm 0,03$ & $1,97 \pm 0,04$ & $2,0 \pm 0,09$ & $1,85 \pm 0,02$ \\
\hline Стебли & $1,32 \pm 0,11$ & $1,03 \pm 0,11$ & $0,97 \pm 0,05$ & $1,32 \pm 0,12$ & $1,53 \pm 0,12$ & $1,56 \pm 0,09$ \\
\hline Корни & $4,63 \pm 0,23$ & $5,07 \pm 0,03$ & $3,58 \pm 0,12$ & $3,95 \pm 0,05$ & $3,26 \pm 0,21$ & $3,57 \pm 0,24$ \\
\hline \multicolumn{7}{|c|}{ Выход алкалоидов (мг/растение) } \\
\hline Листья & $92,66 \pm 4,61$ & $123,54 \pm 1,42$ & $117,43 \pm 3,03$ & $114,65 \pm 1,56$ & $112,01 \pm 2,99$ & $127,21 \pm 2,54$ \\
\hline Стебли & $35,37 \pm 3,85$ & $26,57 \pm 2,34$ & $33,17 \pm 2,65$ & $49,51 \pm 3,88$ & $57,99 \pm 3,96$ & $73,47 \pm 6,57$ \\
\hline Корни & $65,28 \pm 4,49$ & $62,37 \pm 3,87$ & $55,50 \pm 5,12$ & $99,14 \pm 5,93$ & $61,28 \pm 3,81$ & $89,29 \pm 7,13$ \\
\hline
\end{tabular}

Наиболее высокий уровень накопления суммы индольных алкалоидов в листьях $(2,90 \pm 0,06 \%)$ и корнях $(5,07 \pm 0,03 \%)$ отмечен у растений, культивируемых при LED-освещении варианта СД 1 (табл. 2). При данном режиме освещения накопление алкалоидов листьями повышалось в среднем в 1,45 раза по сравнению с люминесцентным освещением. В корнях растений, культивируемых при светодиодном освещении варианта СД 1, стимуляция накопления алкалоидов по сравнению с контролем не была такой значительной. Интересно отметить, что в надземной части растений C. roseus, культивируемых при остальных вариантах светодиодного освещения, уровень накопления алкалоидов был либо схожим, либо более низким, чем в растениях контрольного варианта. В корневой системе C. roseus при данных режимах освещения отмечено достоверное снижение накопления алкалоидов по сравнению с контролем. Возможно, это обусловлено более высокой интенсивностью ростовых процессов и использованием основных предшественников в биосинтезе алкалоидов для синтеза первичных метаболитов и образования структурных компонентов растителной ткани.

В то же время важным является выход алкалоидов в расчете на одно растение. Сравнительный анализ содержания исследуемых фармакологически ценных вторичных метаболитов в целом растении (мг/растение) показал, что наибольшим выходом алкалоидов листьев характеризуются растения C. roseus, культивируемые при светодиодном освещении вариантов СД 1 и СД 4. В первом случае - из-за более высокого уровня биосинтеза и накопления алкалоидов, во втором - вследствие более интенсивного роста и образования сухой массы. Выход суммы алкалоидов листьев растений вариантов СД 1 и СД 4 составляла 123,54 $\pm 1,42$ и 127,21 22,54 мг/растение, соответственно, и в среднем была в 1,4 раза выше, чем в растениях, выращенных при контрольном люминесцентном освещении. Уровень накопления алкалоидов стеблями был равен $73,47 \pm 6,57$. Сумма алкалоидов корней была максимальной в растениях вариантов СД 3 и СД 4 и составляла $99,14 \pm 5,93$ и 89,26 $\pm 7,13$ мг/растение, соответственно, что также в среднем в 1,5 раза выше, чем в контроле.

\section{Заключение}

Таким образом, можно заключить, что представляется возможным культивирование растений и получение сырья C. roseus в условиях LED-освещения, содержащего все части спектра фотосинтетически активной радиации, для получения высокоценных ТИА. Установлено, что культивирование растений $C$. roseus при освещении светом с соотношением C : К, равным $1: 1,3$ и ППФ 200 мкмоль $\mathrm{M}^{-2} \cdot \mathrm{c}^{-1}$, приводит 
к замедлению ростовых процессов, снижению интенсивности цветения и накопления сухой массы. При этом данный режим освещения стимулирует накопление алкалоидов в листьях и корнях и фенольных соединений в листьях и стеблях растений. Растения, культивируемые при освещении с соотношением С : К, равном $1: 4$ (200 и 500 мкмоль $\left.\mathrm{M}^{-2} \cdot \mathrm{c}^{-1}\right)$ характеризовались более высокой интенсивностью роста и цвете-

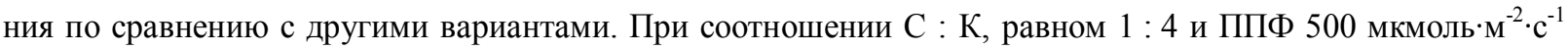
отмечено максимальное накопление растением сухой массы. Для образования корневой системы и накопления в ней алкалоидов эффективными были оба варианта LED-освещения с уровнем ППФ 500 мкмоль $\cdot \mathrm{M}^{-2} \cdot \mathrm{c}^{-1}$, независимо от спектра излучения.

Содержание алкалоидов при данных условиях культивирования варьирует в среднем от 1,85 до 2,90\% в листьях, от 0,97 до 1,56\% в стеблях и от 3,26 до 5,07\% в корнях C. roseus в зависимости от режима освещения. Наибольший выход алкалоидов листьев отмечен в растениях, культивируемых при све-

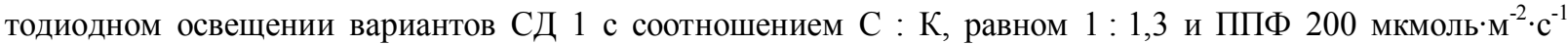
$\left(123,54 \pm 1,42\right.$ мг/растение), а также СД 5 - $1: 4$ и ППФ 500 мкмоль м $^{-2} \cdot \mathrm{c}^{-1}(127,21 \pm 2,54$ мг/растение). Максимальное количество корневых алкалоидов накапливают растения C. roseus, культивируемые при LEDосвещении с максимальной интенсивностью - 500 мкмоль м $^{-2} \cdot \mathrm{c}^{-1}-$ в вариантах СД 3 и СД $5-98,98 \pm 7,93$

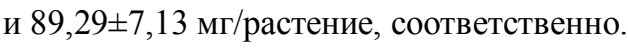

Таким образом, среди протестированных режимов LED-освещения оптимальным для получения алкалоид-содержащего сырья корней и надземной части растений $C$. roseus является вариант с самыми высокими уровнем квантов в красной части спектра и интенсивностью ФАР (с соотношением С : К, равном $1: 4$ и ППФ 500 мкмоль $\left.\cdot \mathrm{M}^{-2} \cdot \mathrm{c}^{-1}\right)$.

\section{Список литературь}

1. Мазнев Н.И. Энциклопедия лекарственных растений. 3-е изд. М., 2004. 496 с.

2. Регистрация лекарственных средств России / под общ. ред. Г.А. Вышковского. 11-е изд. М., 2004. 195 с.

3. Aslam J., Khan S.H., Siddiqui Z.H., Fatima Z., Maqsood M., Bhat M.A., Nasim S.A., Ilah A., Ahmad I.Z., Khan S.A., Mujib A., Sharma M. P. Catharanthus roseus (L.) G. Don. An important drug: it is applications and production // Pharmacie Globale (IJCP). 2010. Vol. 1, N4. Pp. 1-16.

4. Van Bergen M., Snoeijer W. Catharanthus G. Don: The Madagascar periwinkle and related species // Wageningen Agricultural University Papers. 1996. Vol. 96, N3. Pp. 1-120.

5. Loyola-Vargas V.M., Galaz-Avalos R.M., Ku-Cauich R. Catharanthus biosynthetic enzymes: the road ahead // Phytochemistry Reviews. 2007. Vol. 6, N2-3. Pp. 307-339.

6. Van Der Heijden R., Verpoorte R., JG Ten Hoopen H. Cell and tissue cultures of Catharanthus roseus (L.) G. Don: a literature survey // Plant Cell Tissue and Organ Culture. 1989. Vol. 18, N3. Pp. 231-280.

7. Renault J-H., Nuzillard J-M., Crouerour G. L., Thepenier P., Zeches-Hanrot M., Men-Olivier L. L. Isolation of indole alkaloids from Catharanthus roseus by centrifugal partition chromatography in the pH-zone refining mode // Journal of Chromatography A. 1999. Vol. 849. Pp. 421-431.

8. Pan Q., Chen Y., Wang Q., Yuan F., Xing S., Tian Y., Zhao J., Sun X., Tang K. Effect of plant growth regulators on the biosynthesis of vinblastine, vindoline and catharanthine in Catharanthus roseus // Plant Growth Regulation. 2010. Vol. 60, N2. Pp. 133-141.

9. Pereira D.M., Ferreres F., Olivera J.M., Gaspar L., Faria J., Valentao P., Sottomayor M., Andrade P.B. Pharmacological effects of Catharanthus roseus root alkaloids in acetylcholinesterase inhibition and cholinergic neurotransmission // Phytomedicine. 2010. Vol. 17, N8-9. Pp. 646-652.

10. Mustafa N.R., Verpoorte R. Phenolic compounds in Catharantus roseus // Phytochem Rev. 2007. Vol. 6. Pp. $243-258$.

11. Buchvald W., Dedio I., Kozlowski J., Lata B. Hydroponic culture of Catharanthus roseus (L.) G. Don and studies on seed production // Phytochem Rev. 2007. Vol. 6. Pp. 413-417.

12. Fucuyama T., Ohashi-Kaneko K., Watanabe H. Estimation of Optimal Red Light Intensity for Production of the Pharmaceutical Drug Components, Vindoline and Catharanthine, Contained in Catharanthus roseus (L.) G. Don // Enviromental Control in Biology. 2015. Vol. 53, N4. Pp. 217-220.

13. Massa G.D., Kim H-H., Wheeler R.M., Mitchell C.A. Plant productivity in response to LED lighting // HortScience. 2008. Vol. 43, N7. Pp. 1951-1956.

14. Yi Z-L., Huang W-F., Ren Y., Onac E., Zhou G-F., Peng S., Wang X-J., Li H-H. LED lights increase bioactive substunces at low energy costs in culturing fruiting bodies of Cordyceps militaris // Scientia Horticulturae. 2014. Vol. 175. Pp. 139-143.

15. Demotes-Mainard S., Peron T., Corot A., Bertheloot J. Gourrierec J.L., Pelleschi-Travier S., Crespel L., Morel P., Huche-Thelier L., Boumaza R., Vian A., Guerin V., Leduc N., Sakr S. Plant responses to red and far-red lights, applications in horticulture // Environmental and Experimental Botany. 2016. Vol. 121. Pp. 4-21. 
16. Kozai T. Resource use effiiency of closed plant production system with artifiial light: Concept, estimation and application to plant factory // Proceedings of the Japan Academy. Series B, Physical and Biological Sciences. 2013. Vol. 89, N10. Pp. 447-461.

17. Srivastava N.K., Srivastava A.K. Influence of some heavy metals on growth, alkaloid content and composition in Catharanthus roseus L. // Indian Journal of Pharmaceutical Sciences. 2010. Vol. 72, N6. Pp. 775-778.

18. Folin O., Ciocalteu V. On tyrosine and tryptophane determinations in proteins // J. Biol. Chem. 1927. Vol. 73, N2. Pp. 627-650.

19. Cerovic Z.G., Masdoumier G., Ghozlen N.B., Latouche G. A new optical leaf-clip meter for simultaneous nondestructive assessment of leaf chlorophyll and epidermal flavonoids // Physiol. Plant. 2012. Vol. 146, N3. Pp. 251-260.

20. Рокицкий П.Ф. Биологическая статистика. М., 1978. 312 с.

21. Sreevalli Y., Kulkarni R. N., Baskaran K., Chandrashekara R. S. Short communication Increasing the content of leaf and root alkaloids of high alkaloid content mutants of periwinkle through nitrogen fertilization // Industrial Crops and Products. 2004. Vol. 19, N2. Pp. 191-195.

22. Государственный реестр лекарственных средств. Т. 1, Ч. 1. М., 2009. 243 с.

23. Катарантуса розового лист. ВФС 42-1106-81.

Поступило в редакцию 20 декабря 2016 г.

После переработки 18 апреля 2017 г. 
Molchan O.V. ${ }^{I^{*}}$, Privalov V.I. ${ }^{2}$, Petrinchik V.O. ${ }^{l}$, Astasenko N.I. ${ }^{l}$ EFFECTS OF LED LIGHT ON THE GROWTH AND SECONDARY METABOLITE PRODUCTION IN CATHARANTHUS ROSEUS MEDICINAL PLANTS UNDER ARTIFICIAL CULTIVATION

${ }^{I}$ V.F.Kuprevich Institute of Experimental Botany of Tthe National Academy of Sciences of Belarus, Akademicheskaia st., 27 Minsk, 200072 (Republic of Belarus)

${ }^{2}$ Center LED and optoelectronics of National Academy of Science of Belarus, Logoiskii trakt, 22, Minsk, 220012

(Republic of Belarus)

Catharanthus roseus G. Don is an important medicinal plant which accumulates pharmacologically important terpenoid indole alkaloids (TIA) and phenolic compounds. TIA of C. roseus includes more than 130 substances. Ajmalicine and serpentine are used for arterial hypertension treatment. Vinblastine and vincristine are well known as antineoplastic drugs used in chemotherapy of cancer diseases.

Light-Emitting Diodes (LEDs) are modern sources of energy allowing production of the light wavelengths corresponding to the absorption peaks of plants photosynthesis and photomorphogenesis.

Influence of different LED light regimes on the growth and biosynthesis processes in C. roseus was studied. Our results have demonstrated that some LEDs light regimes strongly stimulated $C$. roseus growth, flowering and biomass production. We found different effects of LEDs light regimes on TIA and phenolic compounds accumulations in plant tissues. The LEDs light regimes stimulating of TIA production were determinated. The results of this work can be used in the creation of techniques for optimization of ornamental and medicinal plants cultivation.

Keywords: Catharanthus roseus, Light Emission Diodes (LED) light, Terpenoid Indole Alkaloids (TIA), phenolic compounds.

\section{References}

1. Maznev N.I. Entsiklopediia lekarstvennykh rastenii. [Encyclopedia of medicinal plants]. 3 ed. Moscow, 2004, 496 p. (in Russ.).

2. Registratsiia lekarstvennykh sredstv Rossii. [Registration of medicines in Russia]. Ed. G.A. Vyshkovskii. 11 ed. Moscow, 2004, 195 p. (in Russ.).

3. Aslam J., Khan S.H., Siddiqui Z.H., Fatima Z., Maqsood M., Bhat M.A., Nasim S.A., Ilah A., Ahmad I.Z., Khan S.A., Mujib A., Sharma M.P. Pharmacie Globale (IJCP), 2010, vol. 1, no. 4, pp. 1-16.

4. Van Bergen M., Snoeijer W. Wageningen Agricultural University Papers, 1996, vol. 96, no. 3, pp. 1-120.

5. Loyola-Vargas V.M., Galaz-Avalos R.M., Ku-Cauich R. Phytochemistry Reviews, 2007, vol. 6, no. 2-3, pp. $307-339$.

6. Van Der Heijden R., Verpoorte R., JG Ten Hoopen H. Plant Cell Tissue and Organ Culture, 1989, vol. 18, no. 3, pp. 231-280.

7. Renault J-H., Nuzillard J-M., Crouerour G. L., Thepenier P., Zeches-Hanrot M., Men-Olivier L.L. Journal of Chromatography A, 1999, vol. 849, pp. 421-431.

8. Pan Q., Chen Y., Wang Q., Yuan F., Xing S., Tian Y., Zhao J., Sun X., Tang K. Plant Growth Regulation, 2010, vol. 60, no. 2, pp. 133-141.

9. Pereira D.M., Ferreres F., Olivera J.M., Gaspar L., Faria J., Valentao P., Sottomayor M., Andrade P.B. Phytomedicine, 2010, vol. 17, no. 8-9, pp. 646-652.

10. Mustafa N.R., Verpoorte R. Phytochem Rev., 2007, vol. 6, pp. 243-258.

11. Buchvald W., Dedio I., Kozlowski J., Lata B. Phytochem Rev., 2007, vol. 6, pp. 413-417.

12. Fucuyama T., Ohashi-Kaneko K., Watanabe H. Enviromental Control in Biology, 2015, vol. 53, no. 4, pp. $217-220$.

13. Massa G.D., Kim H-H., Wheeler R.M., Mitchell C.A. HortScience, 2008, vol. 43, no. 7, pp. 1951-1956.

14. Yi Z-L., Huang W-F., Ren Y., Onac E., Zhou G-F., Peng S., Wang X-J., Li H-H. Scientia Horticulturae, 2014, vol. 175, pp. 139-143.

15. Demotes-Mainard S., Peron T., Corot A., Bertheloot J. Gourrierec J.L., Pelleschi-Travier S., Crespel L., Morel P., Huche-Thelier L., Boumaza R., Vian A., Guerin V., Leduc N., Sakr S. Environmental and Experimental Botany, 2016, vol. 121, pp. 4-21.

16. Kozai T. Proceedings of the Japan Academy. Series B, Physical and Biological Sciences, 2013, vol. 89, no. 10, pp. 447-461.

17. Srivastava N.K., Srivastava A.K. Indian Journal of Pharmaceutical Sciences, 2010, vol. 72, no. 6, pp. 775-778.

18. Folin O., Ciocalteu V. J. Biol. Chem., 1927, vol. 73, no. 2, pp. 627-650.

19. Cerovic Z.G., Masdoumier G., Ghozlen N.B., Latouche G. Physiol. Plant., 2012, vol. 146, no. 3, pp. 251-260.

20. Rokitskii P.F. Biologicheskaia statistika. [Biological Statistics]. Moscow, 1978, 312 p. (in Russ.).

21. Sreevalli Y., Kulkarni R.N., Baskaran K., Chandrashekara R.S. Industrial Crops and Products, 2004, vol. 19, no. 2, pp. 191-195.

22. Gosudarstvennyi reestr lekarstvennykh sredstv. [State Register of Medicines]. vol. 1, part. 1. Moscow, 2009,243 p. (in Russ.).

23. Katarantusa rozovogo list. VFS 42-1106-81. [Catarratus rose leaf. FFS 42-1106-81]. (in Russ.).

Received December 20, 2016

Revised April 18, 2017

\footnotetext{
* Corresponding author.
} 